\title{
Mechanical properties and morphological characteristics of ARALL reinforced with TRGO doped epoxy resin
}

\author{
Propiedades mecánicas y características \\ morfológicas de ARALL reforzado con \\ TRGO dopando su resina epóxica
}

\author{
Alberto Monsalve ${ }^{1,3}$, Luis Parra ${ }^{3}$, Diego Baeza ${ }^{3}$, \\ Roberto Solís ${ }^{1,3}$, Humberto Palza ${ }^{2}$
}

\footnotetext{
${ }^{1}$ Departamento de Ingeniería Metalúrgica, Universidad de Santiago de Chile, Av. Libertador Bernardo O’Higgins 3363, Santiago, Santiago, Chile.

${ }^{2}$ Laboratorio de Polímeros, Facultad de Ciencias Físicas y Matemáticas, Universidad de Chile, Av. Beaucheff 851, Santiago, Santiago, Chile.

${ }^{3}$ CIDCA, Centro de Investigación y Desarrollo en Ciencias Aeroespaciales Academia Politécnica Aeronáutica, Fuerza Aérea de Chile, Av. José Miguel Carrera 11087, El Bosque, Santiago, Chile.

e-mail: alberto.monsalve@usach.cl, roberto.solis@usach.cl,hpalza@ing.uchile.cl,lparram.lp@gmail.com, diego.baeza.m@gmail.com
}

\begin{abstract}
Mechanical properties in tension, bending, fatigue and lap-shear in two different proportions $(0.5 \%$ wt and 1\%wt) of TRGO (Thermally Reduced Graphite Oxide) doped ARALL (Aramid Aluminium Laminate) were examined. The materials and their failure modes were characterized morphologically by examination through SEM (Scanning Electron Microscopy). Some mechanical properties of ARALL were improved when doped with $0.5 \%$ of TRGO, showing a significant increase of fatigue properties, as well as a change in fracture surface morphology. Tension and bending properties showed variable results and further studies should be carried out to arrive to definitive conclusions, while lap-shear testing showed lower shear values. The results were statistically validated through mono-factorial variance analysis. Comparing the present results with previous work on CNT (Carbon Nanotubes) doped ARALL, it can be stated that: (a) TRGO doped ARALL showed improved fatigue properties when compared with non-doped ARALL, but in a less effective way than doping with CNT, (b) TRGO doped ARALL tension properties showed no significant variation as compared with ARALL alone, showing no deleterious influence as in the CNT doping case, (c) TRGO doped ARALL bending properties resulted better than non-doped ARALL, but similar than those obtained when doping with CNT and (d) TRGO decreased the adherence between aramid fiber impregnated L20 epoxy resin and aluminium. These last results are sustained based on observed improvements as a percentage value, without a statistical variance analysis made on CNT doped ARALL.
\end{abstract}

Keywords: Thermally Reduced Graphite Oxide (TRGO), Al 2024, Fatigue, Tension, Bending.

\section{RESUMEN}

Se estudiaron las propiedades mecánicas de ARALL (Aramid Aluminium Laminated) al ser reforzado con dos dosificaciones ( 0.5 y $1 \%$ en peso) de TRGO (Thermically Reduced Graphite Oxide), en busca de aumentar las propiedades mecánicas de este material compuesto en tracción, flexión, fatiga y Lap Shear. Los resultados mostraron un aumento en algunas de las propiedades mecánicas de ARALL al ser dopado con TRGO, principalmente en el material que fue reforzado con $0,5 \%$, destacando un cambio en la morfología de fractura de la superficie del aluminio, así como también un aumento significativo de la resistencia a la fatiga del material, tema de gran interés principalmente para el mundo aeronáutico. Otras propiedades como resistencia a la tracción y flexión presentaron resultados variables, siendo necesario un mayor estudio para poder definir el efecto de la cantidad de refuerzo sobre la respuesta entregada por el material estudiado. En el caso de lapshear, se presentó una disminución en la resistencia al corte de la resina con la dosificación de 0.5\% TRGO. 
Los resultados obtenidos fueron validados estadísticamente mediante el análisis de varianza unifactorial. Al comparar los resultados obtenidos con los de estudios anteriores donde se utilizaron nanotubos de carbono (NTC), se puede concluir que: (a) en fatiga el TRGO se mostró menos efectivo que los NTC en la mejora de vida útil; (b) en tracción el TRGO no presentó variaciones importantes a diferencia de los NTC que disminuyen considerablemente las propiedades mecánicas, (c) en flexión el TRGO no presentó una eficiencia respecto a la obtenida con NTC y (d) el TRGO disminuyó la adherencia de la resina epoxy L20 impregnada con fibra de aramida al aluminio. Estas conclusiones se basan en mejoras porcentuales, ya que no existe un sustento estadístico que respalde los resultados obtenidos en los trabajos que se utilizaron NTC.

Palabras clave: TRGO (Thermally Reduced Graphite Oxide), Al 2024, Fatiga, Tracción, Flexión.

\section{INTRODUCTION}

Composite materials are nowadays being explored in many engineering fields, like car-making, ship-building and aviation. Their dynamic development continually proposes new materials with better characteristics and properties, every time at a lower cost. Composite materials started to be used in commercial and civil aviation at the beginning of the 70 's.

During the last 12 years graphene has had an enormous development, as the material of the future, as highlighted by Asdrúbal [1] in his publication from 2011. Graphene has been established as the fundamental structure of graphite as a one-atom-thin layer of an hexagonal crystal structure, as showed by Andre Geim and Konstantin Novoselov in 2006, and worth their Nobel Prize. According to Geim [2], graphene is the fundamental structure of graphite and also of the Carbon Nanotubes (CNT), which present themselves as a transparent one-atom-thin bi-dimensional sheet rolled up in the form of a cylinder. From this, graphite can be assumed to be composed of successive graphene sheets held together by weak links. Graphene has also superior mechanical and electronic properties than CNT. Nevertheless synthetizing graphene in large sheets is very expensive. Therefore, the use of graphene as a powder or as nano-platelets are the closest to have good properties at a reasonable cost. In this chemical synthesis, strong reagents which oxidizes graphite are used, followed by a high temperature thermal shock to eliminate oxygen.

The need to locally develop airplane repair technology, promotes studies in the context of a project named "Development of the damage tolerance criteria for an ageing fleet", as new proposals to reinforce composite materials. Investigations of Maturana and Morales [3] and Garlaschi [4] have been locally carried out based on the influence of mechanical properties of ARALL, a Fiber-Metal Laminate material reinforced through doping with CNT. Garzón [5] suggests that graphene nano-platelets can replace CNT in reinforcing thermo-plastic materials as polypropylene or thermo-stable materials like epoxy resin, with the advantage of lower costs. Tang et al. [6] (2013) have investigated the effect of graphene dispersion in the mechanical properties of graphene/epoxy composites, finding that the composite with highly dispersed reduced graphite oxide, showed higher strength than those with poorly dispersed RGO (Reduced Graphite Oxide). Rafiee et al. [7] (2009), investigated the influence of a nanocomposite with low graphene content, on the mechanical properties. The mechanical properties measured were Young modulus, ultimate tensile strength, fracture toughness, fracture energy and the fatigue resistance to crack propagation, finding better results in those cases where graphene was used as reinforcing material in comparison with those cases where carbon nanotubes were used. Also, this group [8] (2010) has studied the fracture and fatigue properties of graphene nanocomposites, showing that the addition of $0.125 \mathrm{wt} \%$ of graphene produces an increment of $65 \%$ in the material fracture toughness. Potts et al. [9] (2011) have investigated graphene-based polymer nanocomposites showing that the mean properties (mechanical, electrical, rheological and so on), are strongly dependent upon the intrinsic properties of graphene-based materials and their state of dispersion in the matrix. Liu et al. [10] (2012) working with GO (Graphite Oxide) reinforced epoxy resin nanocomposites, studied mechanical properties by means of three-point bending tests, impact tests, dynamic mechanical analysis and thermogravimetric analysis. They found that significant improvements in flexural strength, flexural modulus and impact strength where achieved when incorporating $1 \mathrm{wt} \%$ of graphene oxide. Kim et al. [11] (2010) analysed the electrical, thermal and mechanical properties of graphene/polymer nanocomposites, using analytical techniques to characterize particle dimensions and surface characteristics of the composite material. Curing process has been also investigated. Qiu et al. [12] (2011) studied the effects of graphene oxides on the cure behavior of an epoxy resin by means of dynamic differential scanning calorimetry and thermogravimetric analysis, finding that the initial reaction temperature and exothermal peak temperature decreased with increase GO contents. Also, the presence of GO significantly hindered the occurrence of vitrification. Finally some reviews have been published in the last years. Sengupta et al. [13] (2011) published a review of the mechanical and electrical properties of graphite and modified graphite reinforced polymer composites. Also Atif et al. 
[14] (2016) have reviewed the mechanical, thermal and electrical properties of graphene-epoxy nanocomposites. Other review of particular interest is the study of graphene reinforced materials made by Domun et al. [15] (2015) who studied the improving in fracture toughness and strength of epoxy resins by means of different reinforcing particles such as, carbon nanotubes and graphene.

The present work evaluates the mechanical properties of ARALL doped with TRGO, and compares the results with data of CNT doped ARALL. Mechanical properties were characterized in tension, bending, fatigue and lap-shear testing for non-doped samples, $0.5 \mathrm{wt} \%$ and $1 \mathrm{wt} \%$ TRGO doped material.

\section{MATERIALS AND METHODS}

For tensile, bending and fatigue testing, samples were prepared using $0.5 \mathrm{~mm}$ thickness of 2024-T3 aluminium bare sheets with rolling direction in the longitudinal direction, while for lap-shear testing, samples were prepared with $1.6 \mathrm{~mm}$ thickness aluminium sheet. The 2024-T3 aluminium bare sheets were subjected to surface treatment prior to the ARALL preparation, first for chemical dimensional adjustment, and then followed by chromic anodizing. The Al 2024-T3 alloy is normally used in aeronautics for airplane bodies. The main alloying elements are copper and magnesium, contributing to strength through aging phenomena. The T3 thermal treatment consists in homogenization, quenching, cold work and natural aging. The chemical composition of 2024-T3 aluminium bare sheets are shown in Table 1.

Table 1: Chemical composition of 2024-T3 aluminium bare sheet.

\begin{tabular}{l|l|l|l|l|l|l}
\hline $\mathbf{A l}(\%)$ & $\mathrm{Si}(\%)$ & $\mathbf{F e}(\%)$ & $\mathbf{C u}(\%)$ & $\mathbf{M n}(\%)$ & $\mathbf{M g}(\%)$ & $\mathbf{Z n}(\%)$ \\
\hline 93 & 0.06 & 0.19 & 4.5 & 0.66 & 1.6 & 0.16 \\
\hline
\end{tabular}

The number of samples chosen was such that a statistical calculation would permit an appraisal of the significance of the measured changes in the different results, as shown in Table 2.

Table 2: Number of samples for each type of mechanical testing.

\begin{tabular}{l|l|l|l}
\hline TEST & $\begin{array}{l}\text { SAMPLES PER } \\
\text { TEST GROUP }\end{array}$ & $\begin{array}{l}\text { TOTAL NUMBER } \\
\text { OF SAMPLES }\end{array}$ & $\begin{array}{l}\text { SAMPLES FOR SEM } \\
\text { OBSERVATION }\end{array}$ \\
\hline Tension & 5 & 15 & 3 \\
\hline Bending & 10 & 30 & 3 \\
\hline Fatigue & 15 & 45 & 3 \\
\hline Lap-shear & 5 & 15 & 3 \\
\hline
\end{tabular}

L20 epoxy resin and EPH-161 (VE3261) hardener was used to prepare ARALL. Aramid fibre was set bidirectional with fibre at 0 and 90 deg and TRGO nano-platelets were added to the hardener, which presents lower viscosity, facilitating the mixing. After 3 minutes manual mixing, an ultrasound bath was used during 20 minutes to assure homogeneous dispersion.

Graphene nano-platelets were prepared by the modified Hummers method at the Chemical Laboratory, Faculty of Physical Sciences and Mathematics, University of Chile.

ARALL preparation was done through a manual sandwich wet-laying rolling procedure commonly used for manufacturing composite materials. Epoxy resin was applied with a brush and rolling was done at room temperature, followed by one or several curing time lapses.

\subsection{Testing conditions and evaluation methodology}

Tension tests were carried out in the laboratories of National Aeronautics Company (ENAER) on a $300 \mathrm{KN}$ WDW-300E Time screw machine, and data analysis was performed through WINWDW software. According to ASTM D 3039/D-08 tension test speed was set to $0.37 \mathrm{~mm} / \mathrm{min}$.

Bending tests were carried out according to ASTM D 790-10 standards, at the laboratories of Metallurgical and Materials Engineering Services of University of Santiago of Chile (SIMET USACH) in a TiniusOlsen model L machine with a capacity up to $300 \mathrm{kN}$. 
Fatigue test were made according to ASTM E 647-13 standard, at the laboratories of SIMET-USACH, on a Mikrotron-Rumul testing machine. Samples were pre-cracked for $4 \mathrm{~mm}$, and crack development controlled up to $15 \mathrm{~mm}$ length. Table 3 shows the different applied loads for fatigue testing.

Table 3: Charge levels for fatigue testing.

\begin{tabular}{l|l|l|l|l|l}
\hline LOAD LEVEL & $\begin{array}{l}\text { MINIMUN LOAD } \\
(\mathbf{k N})\end{array}$ & $\begin{array}{l}\text { MAXIMUM LOAD } \\
\mathbf{( k N})\end{array}$ & $\begin{array}{l}\text { AVERAGE LOAD } \\
\mathbf{( k N )}\end{array}$ & $\begin{array}{l}\text { LOAD RANGE } \\
\mathbf{( k N})\end{array}$ & LOAD RATIO \\
\hline I & 0.67 & 1.3 & 1.0 & 0.67 & 0.5 \\
\hline II & 0.80 & 1.6 & 1.2 & 0.80 & 0.5 \\
\hline III & 0.93 & 1.9 & 1.4 & 0.93 & 0.5 \\
\hline IV & 1.1 & 2.1 & 1.6 & 1.1 & 0.5 \\
\hline V & 1.2 & 2.4 & 1.8 & 1.2 & 0.5 \\
\hline
\end{tabular}

Lap-shear tests were carried out in the laboratories of ENAER on a Time model WDW-300E machine, with capacity up to $300 \mathrm{kN}$, the same used for tension testing. According to ASTM 1002-10, testing speed was set to $1.3 \mathrm{~mm} / \mathrm{min}$.

Material characterization was done through microstructural analysis by SEM (scanning electron microscopy) of the samples after mechanical testing. Fracture surfaces were also characterized. The analysed zones in fatigue samples were limited to the $11 \mathrm{~mm}$ of crack advance before fracture. Images were evaluated both by secondary electrons (SEI) and backscattered electrons (BES).

In tension testing samples failure modes were established according to ASTM D 3039/D-08.

Evaluation methodology includes testing results presented graphically through OriginPro 9 software of OriginLab. All results were statistically evaluated with MiniTab17 software to characterize if the differences observed in the mechanical properties are or not significant.

\section{RESULTS AND DISCUSSIONS}

Tension test results are presented in Figure 1 showing the stress-strain curves for non-doped, $0.5 \mathrm{wt} \%$ TRGO doped and $1 \mathrm{wt} \%$ TRGO doped ARALL.

Point A in Figure 1 shows the linear behaviour in the elastic range of deformation of the material up to the yield point. Plastic deformation continues up to point $\mathrm{B}$, where deformation hardening decreases to a lower value. Up to this point can be considered wholesome, it corresponds to the beginning of failure of the epoxy resin and to the fact that the aramid fibres start to be the main resistance of the applied load. This continues up to Point $\mathrm{C}$, the ultimate tensile strength (UTS). At this point the aramid fibres fail and the applied load abruptly decreases. From this point on, the load is supported only by the aluminium sheet and complete failure is soon attained at point $\mathrm{D}$.

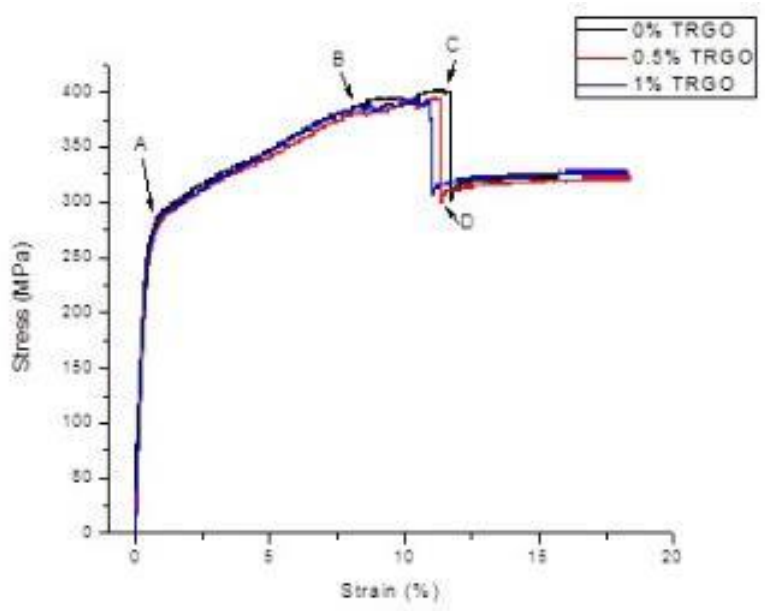

Figure 1: Stress-Strain curves for non-doped and TRGO doped ARALL. 
Results are summarized in Table 4 showing both average values and standard deviation of yield strength, UTS and Young's elastic modulus.

Table 4: Tension test of non-doped, $0.5 \%$ and $1 \mathrm{wt} \%$ TRGO doped ARALL.

\begin{tabular}{l|l|l|l|l}
\hline TEST GROUP & & $\begin{array}{l}\text { YIELD STRENGTH } \\
(\mathbf{M P a})\end{array}$ & UTS (MPa) & $\begin{array}{l}\text { EXPERIMENTAL YOUNG'S } \\
\text { MODULUS (GPa) }\end{array}$ \\
\hline \multirow{2}{*}{$\begin{array}{l}\text { Non-doped } \\
\text { ARALL }\end{array}$} & Average & 267 & 398 & 54.4 \\
\cline { 2 - 5 } & Std. dev. & 7.13 & 6.03 & 3.41 \\
\hline $\begin{array}{l}\text { } \\
\text { doped ARALL }\end{array}$ & Average & 275 & 392 & 48.5 \\
\cline { 2 - 5 } $\begin{array}{l}1 \% \quad \text { TRGO dev. } \\
\text { doped ARALL }\end{array}$ & Average & 27.79 & 7.33 & 1.85 \\
\cline { 2 - 5 } & Std. dev. & 6.99 & 389 & 51.2 \\
\hline
\end{tabular}

Microstructural characteristics of failure of tensile test samples are shown in Figure 2. The images show BES images of delaminated samples due to the composite failure. While in most samples aluminium and aramid fibres did not fail in the same place, the samples subjected to analysis were chosen from those where failure was homogeneous. Non-doped ARALL showed ductile failure in aluminium. In all TRGO doped samples, resin showed to remain adhered to aluminium rather than to the aramid fibres.

Figure 2a) shows the failure of a non-doped sample with the fractured aluminium sheet on the right side of the picture and the longitudinally failed aramid fibers. In the internal surface of the aluminium sheet some epoxy resin is seen. Figure 2b), corresponds to a 1\% TRGO doped ARALL sample after tension testing, shows less damage of the aramid fiber and a great quantity of resin in the internal side of the aluminium.
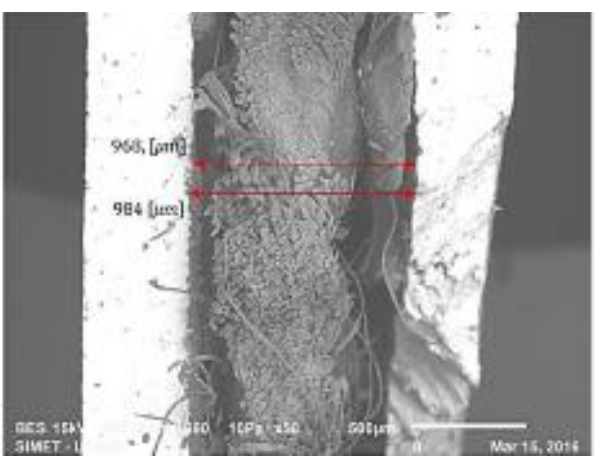

a)
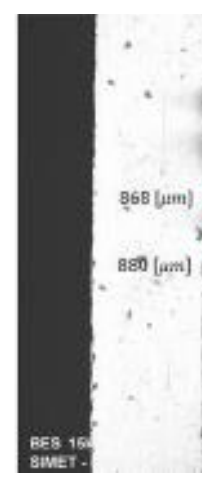

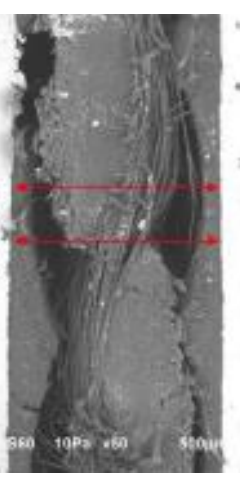

b)

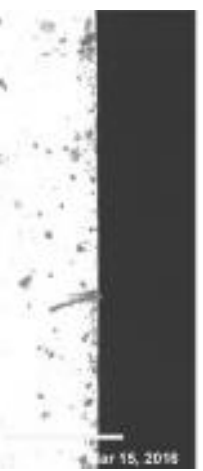

at is, 2015

Figure 2: Failure characteristics of tensile test simple fractures: a) non-doped ARALL and b) $1 \%$ TRGO doped ARALL.

Fracture surfaces, illustrated in Figure 3, display similar characteristics in all samples, showing no significant differences. The presence $\mathrm{Al}_{2} \mathrm{CuMg}$ inclusions, typical of aluminium 2024-T3 alloys, are depicted as white second phase particles. Ductile dimples coexist with brittle areas due to inclusion of decohesion surfaces. 


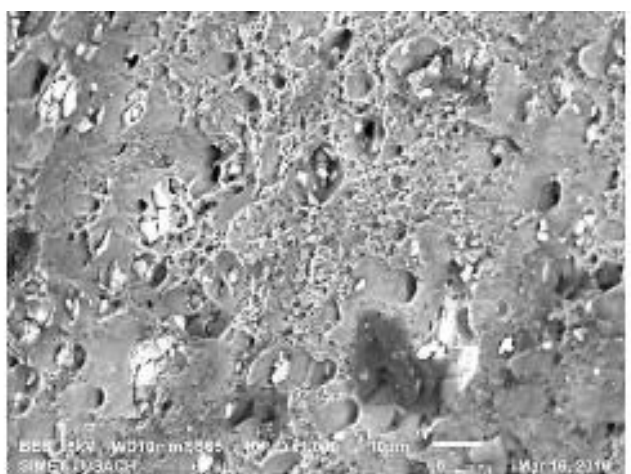

a)

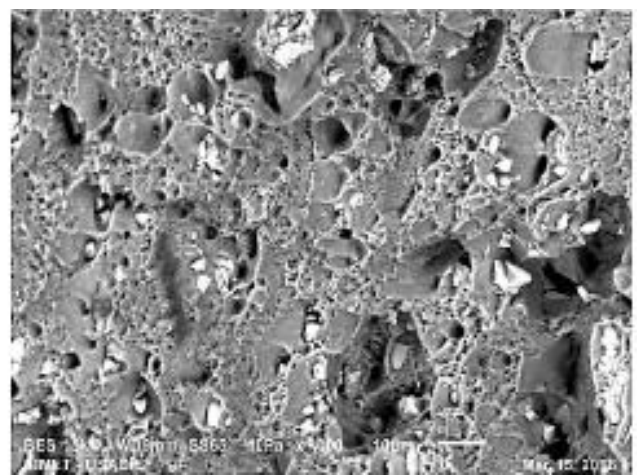

b)

Figure 3: Characteristics of fracture surfaces of aluminium 2024-T3: a) non-doped ARALL and b) 1 wt $\%$ TRGO doped ARALL.

Bending test results are shown in Figure 4. In this test, the elastic slope of the load-deflection curve, maximum load, elastic modulus and maximum deflection are measured.

The measured values are detailed in Table 5. Elastic modulus decreases as TRGO doping increases, while maximum deflection improves.

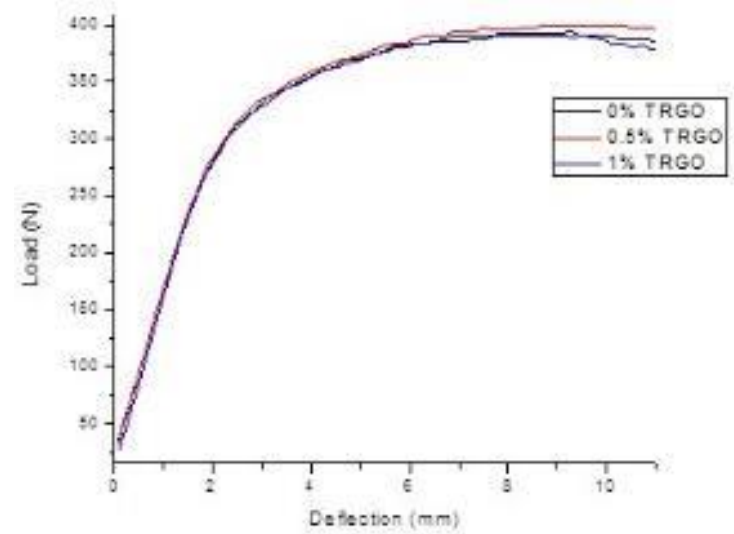

Figure 4: Load-deflection curves for non-doped and TRGO doped ARALL.

Table 5: Bending test results of non-doped and TRGO doped ARALL.

\begin{tabular}{|c|c|c|c|c|c|}
\hline TEST GROUP & & $\begin{array}{l}\text { ELASTIC SLOPE } \\
(\mathrm{N} / \mathrm{mm})\end{array}$ & $\begin{array}{l}\text { MAXIMUM } \\
\text { LOAD (N) }\end{array}$ & $\begin{array}{l}\text { E }_{\mathrm{B}} \text { ELASTIC MOD- } \\
\text { ULUS (GPa) }\end{array}$ & $\begin{array}{l}\text { MAXIMUM DEFLECTION } \\
(\mathrm{mm})\end{array}$ \\
\hline \multirow{2}{*}{$\begin{array}{l}\text { Non-doped } \\
\text { ARALL }\end{array}$} & Average & 146 & 384 & 63.5 & 2.6 \\
\hline & Std. dev. & 4.84 & 8.61 & 2.11 & 0.08 \\
\hline \multirow{2}{*}{$\begin{array}{l}0.5 \% \quad \text { TRGO } \\
\text { doped }\end{array}$} & Average & 143 & 399 & 62.8 & 2.8 \\
\hline & Std. dev. & 5.92 & 11.8 & 2.86 & 0.10 \\
\hline \multirow{2}{*}{$\begin{array}{lc}1 \% & \text { TRGO } \\
\text { doped } & \text { ARALL }\end{array}$} & Average & 133 & 380 & 58.1 & 2,9 \\
\hline & Std. dev. & 1.69 & 5.38 & 0.740 & 0.05 \\
\hline
\end{tabular}

Figure 5 shows the post-test bending samples. Characterization was made by primary electrons, in the maximum deflection zone of each sample. A slight delamination of the resin matrix of the aluminium is shown at the right side of Figure 5a). Also, some thinning of one of the aluminium sheets can be observed, the typical deformation of bending test samples, due to the tension and compression stresses of the lower and upper sheet respectively. Fibre is well impregnated by resin, as shown as the white areas in the fibres. This behaviour is repeated in the TRGO doped samples, showing delamination of the material and a good resin impregnation of the fibres. 


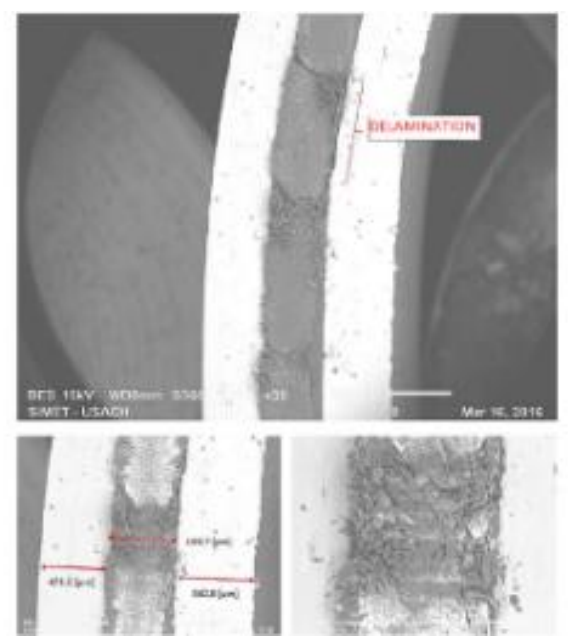

a)

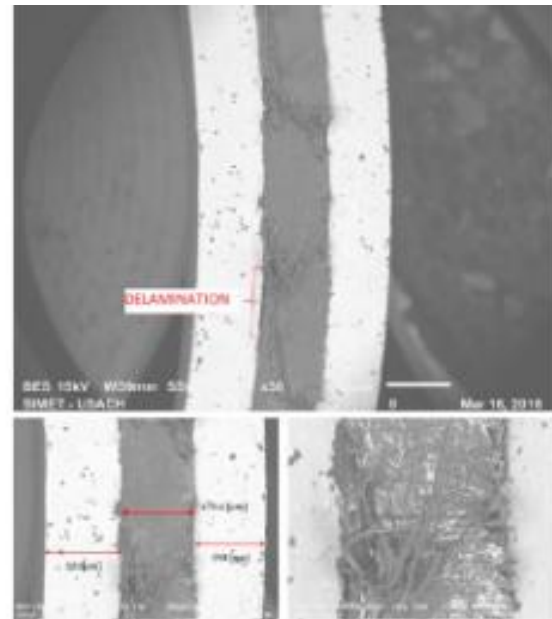

b)

Figure 5: Maximum deflection zone of bending test samples: a) non-doped ARALL and b) 1 wt $\%$ TRGO doped ARALL.

The fatigue results, presented in S-N diagrams (Wohler curves), can be seen in Figure 6, (in this study, load versus number of cycles in a logarithmic scale).

As expected, TRGO doping of ARALL shows an important variation on fatigue properties. The results of $0.5 \mathrm{wt} \%$ TRGO doping shows better results than $1 \mathrm{wt} \%$ TRGO doping and as load increases, the number of required cycles for crack growth decreases.

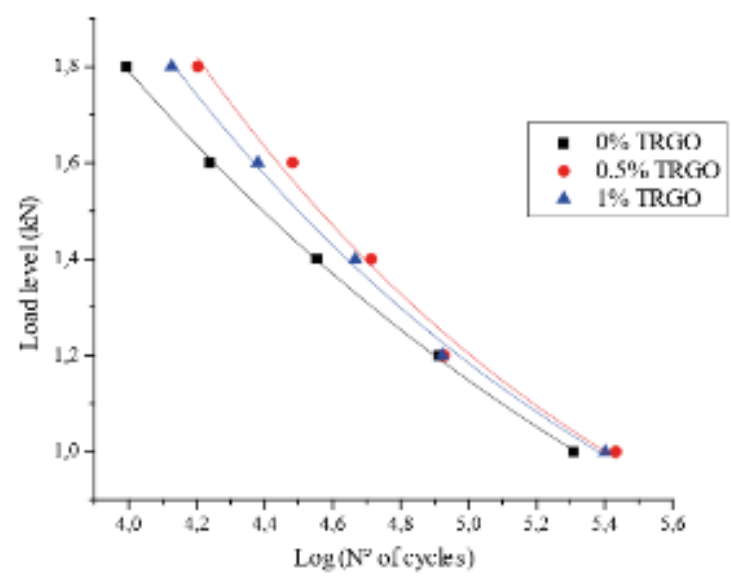

Figure 6: Fatigue response of the non-doped and TRGO doped ARALL.

Microstructural analysis of fatigue test samples, are shown in Figure 7. Secondary and primary electron images are of the same zone and primary image corresponds to a general view. Fatigue test samples, mainly those doped with $0.5 \mathrm{wt} \%$, showed a reduced presence of fatigue striations in aluminium. 

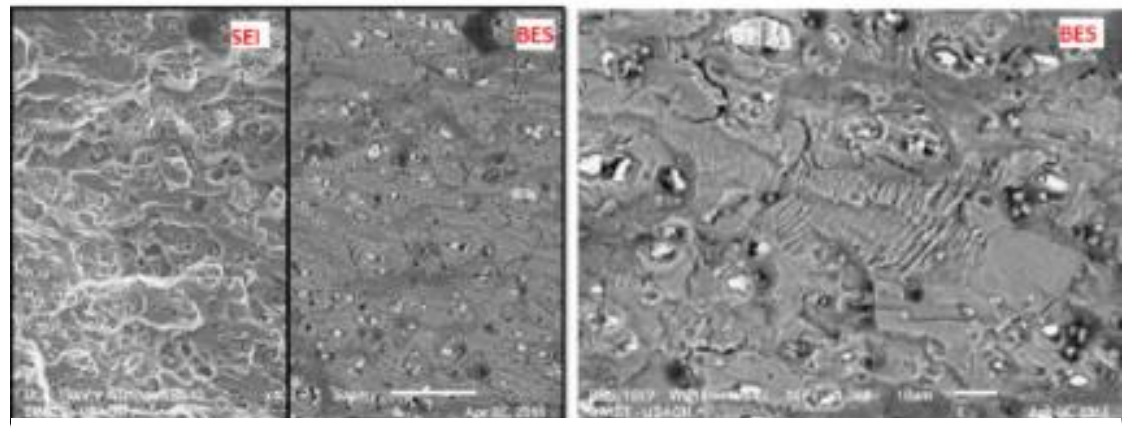

a)
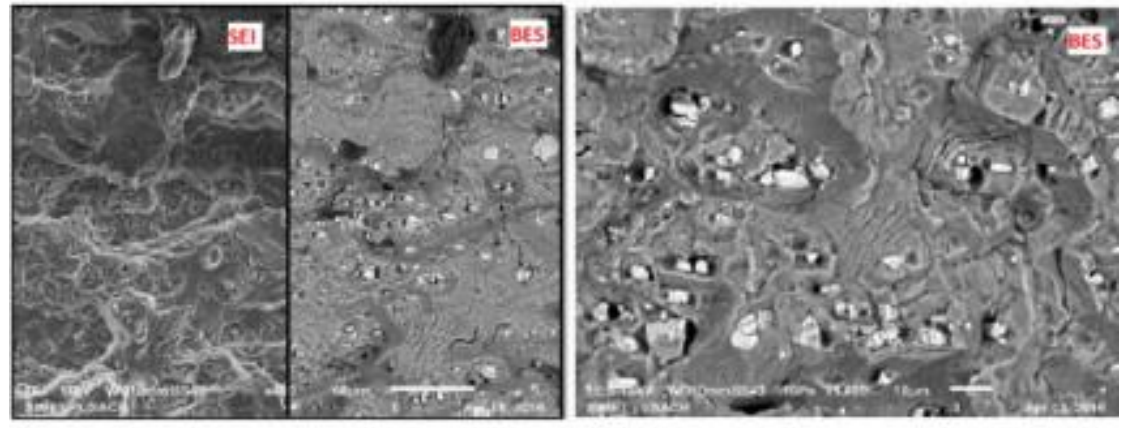

b)

Figure 7: Fracture surfaces of samples after fatigue testing: a) non-doped ARALL and b) 1 wt $\%$ TRGO doped ARALL.

Lap-shear tests were used to study the adherence of the different materials used in these composites. From this test it is possible to obtain the applied shear stress as a function of the position of the tensile machine crosshead. Results are presented in Figure 8, showing the shear stress-displacement curves for samples of non-doped, $0.5 \mathrm{wt} \%$ TRGO doped and $1 \mathrm{wt} \%$ TRGO doped ARALL. The TRGO doped ARALL loses adherence with less applied load than the non-doped material.

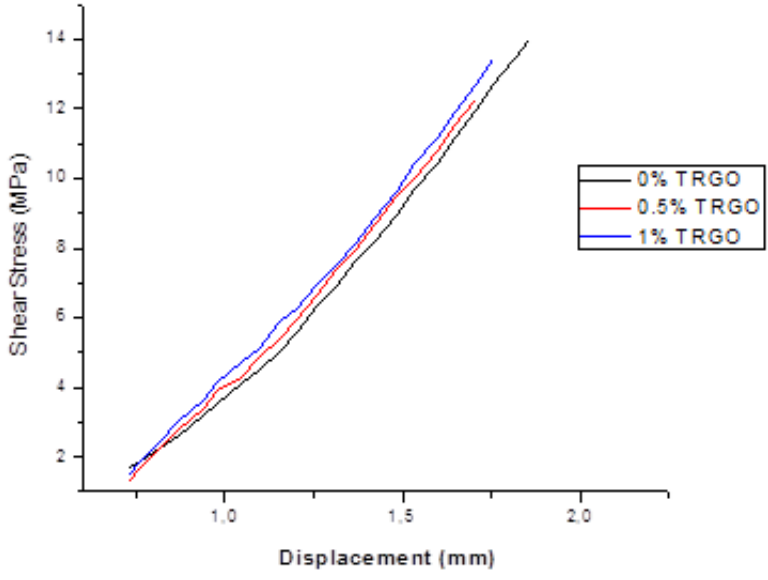

Figure 8: Lap-shear response of the non-doped and TRGO doped ARALL.

Results, summarized in Table 6, show both, average values and standard deviation of maximum shear stress. 
Table 6: Lap-shear test results of non-doped and TRGO doped ARALL.

\begin{tabular}{l|l|l}
\hline TEST GROUP & & $\begin{array}{l}\text { MAXIMUM SHEAR } \\
\text { STRESS (MPa) }\end{array}$ \\
\hline \multirow{2}{*}{$\begin{array}{l}\text { Non-doped } \\
\text { ARALL }\end{array}$} & Average & 14 \\
\cline { 2 - 3 } $0.5 \% \quad$ Ttd. dev. & 0.84 \\
\hline $\begin{array}{l}\text { doped ARALL } \\
1 \% \quad \text { TRGO }\end{array}$ & Average & 12 \\
\cline { 2 - 3 } doped ARALL & Average & 0.51 \\
\cline { 2 - 3 } & Std. dev. & 0.65 \\
\hline
\end{tabular}

Microstructural analysis of the different test specimens characterized the contact surfaces between the aluminium sheets and the fiber/resin matrix. In most of the specimens, failure morphology showed an adherence failure of one of the aluminium sheets detaching it completely. Figure 9 illustrates the results. The detached aluminium sheet is shown on the upper side of the figure, where the dark areas represent the resin still adhering to the aluminium surface and the bare aluminium surface shows a white area. The fiber/resin side is presented on the lower side of the figure, showing the aramid textile with the fibres both in the longitudinal and in the transverse directions. Over the textile, some rests of resin can be observed.

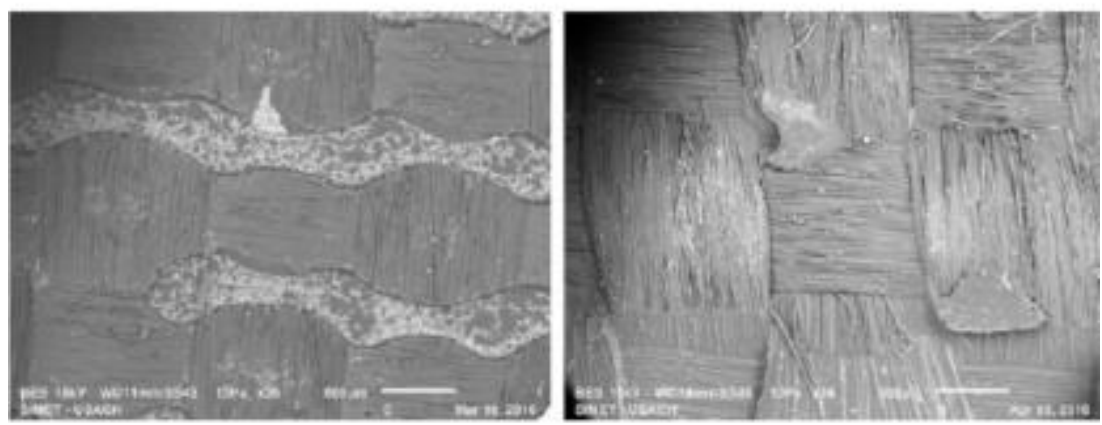

a)
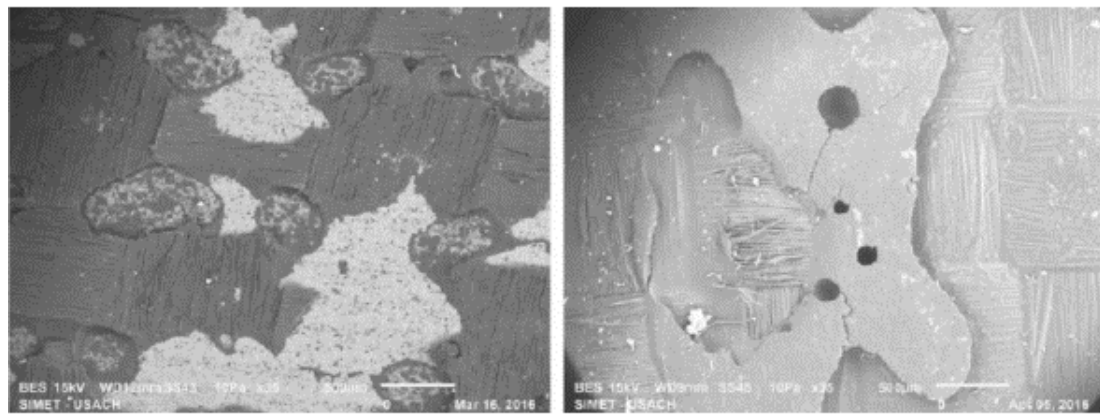

b)

Figure 9: Lap-shear test specimens after testing. Aluminium sheet surface on the upper side and fiber/resin matrix surface on the lower side: a) non-doped ARALL and b) 1 wt $\%$ TRGO doped ARALL. following:

The changes of mechanical properties as a function of the TRGO doping content are discussed in the

Tensile tests: average results as a function of TRGO doping is shown in Figure 10 for Yield Strength, Ultimate Tensile strength and Young's Modulus. 


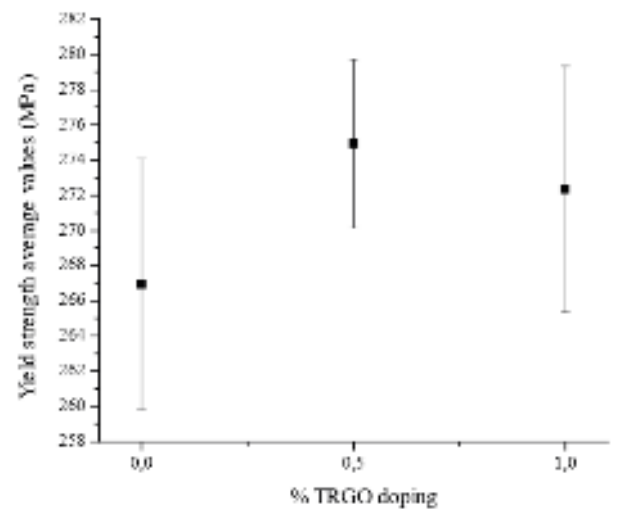

a)

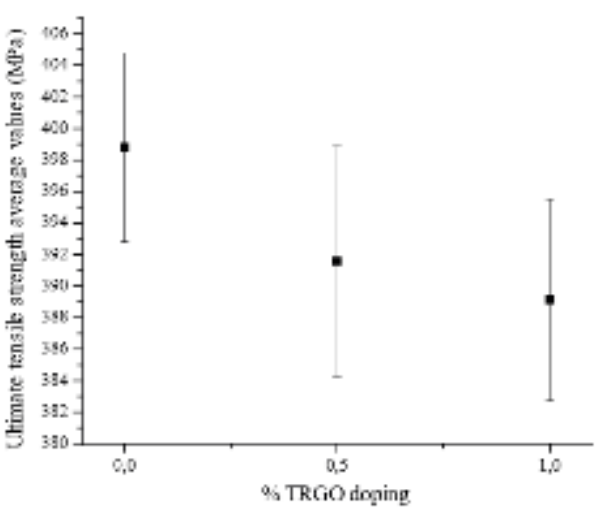

b)

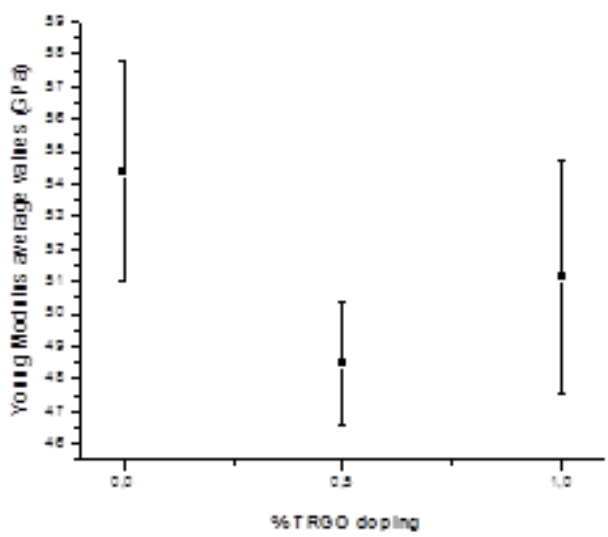

c)

Figure 10: ARALL tension properties evolution with \% TRGO doping: a) Yield strength, b) UTS and c) Young's Modulus.

Tensile test results analysis shows that the yield strength and UTS obtained for different TRGO doping are very similar. The statistical evaluation of the data through the ANalysis Of VAriance (ANOVA) tables and the Tukey method, shows with $95 \%$ of certitude that there is not possible to show that the values for yield stress and UTS are statistically different.

On the contrary, Young's modulus is seriously affected by $0.5 \mathrm{wt} \%$ TRGO doping, decreasing its value by almost $11 \%$. Higher contents of TRGO seems to increase the Young's modulus, in agreement with the intrinsic stiffness associated to TRGO. This phenomenon does not match the expected results and, according to the observations, this should be caused by the nanometric size of the TRGO-platelets added to the resin.

Bending tests: The effect of TRGO doping on bending properties is shown in Figure 11. The improvement of maximum load associated to $0.5 \mathrm{wt} \%$ TRGO doped ARALL can be considered significant, but not so for $1 \mathrm{wt} \%$ TRGO doping, which shows an improvement not statistically significant in comparison with non-doped material. As for maximum deflection improvement TRGO doping resulted always significant. Finally, $\mathrm{E}_{\mathrm{b}}$ decreasing resulted significant only for $1 \mathrm{wt} \%$ TRGO doped ARALL. 


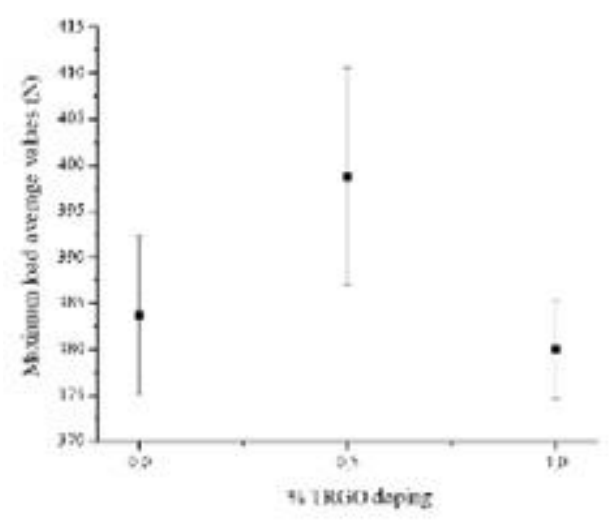

a)

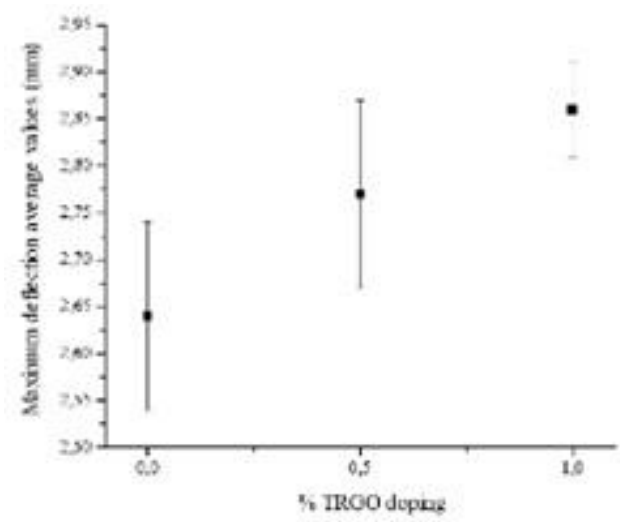

b)

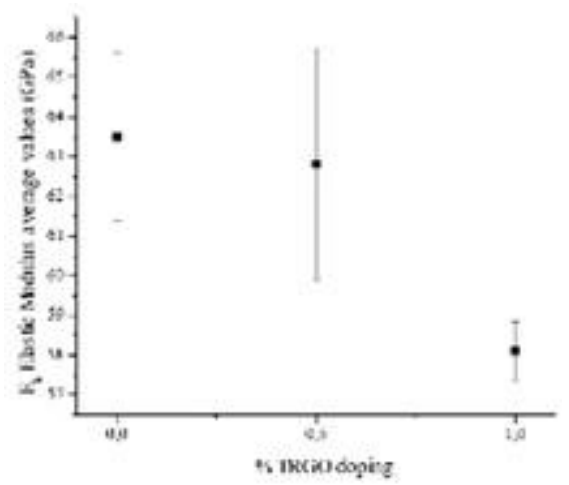

c)

Figure 11: ARALL bending properties evolution with \% TRGO doping: a) Maximum load, b) Maximum deflection c) $E_{b}$ elastic modulus.

Fatigue results: The main effect of TRGO doping was an interesting gain in fatigue life when $0.5 \mathrm{wt} \%$ TRGO doped ARALL was used, for all the tested load levels. As shown, the improvement in fatigue life was quite important, mainly for the $0.5 \mathrm{wt} \%$ TRGO doping, where the highest value reached $70 \%$ corresponding to the maximum load applied.

The statistical analysis of TRGO doping of ARALL confirms this idea, rendering a significant result of the ANOVA tables analysed by the Tukey method. Results showed that there is a significant improvement with TRGO doping ARALL.

Microstructural analysis (see Figure 7) of the fatigue test samples shows that damage was always limited to the aluminium sheets, where the main characteristics are delamination of the ARALL constituents limited to the fracture zones. This is mainly due to the fact that the fiber transfers the cyclic stress through the epoxy resin to the metallic surface, specifically where the presence of a discontinuity causes stress concentration.

The already shown images describe a common behaviour of both, the non-doped and the TRGO doped ARALL, which is the simultaneous presence of dimples revealing the ductility of aluminium and the micro-cleavage zones with striations due to the propagating cracks at each fatigue cycle.

Lap-shear tests: the objective of these tests was to measure the material adherence when subject to shear stresses only. Lap-shear test evolution results with TRGO doping is shown in Figure 12. The statistical analysis of the obtained results clearly shows that $0.5 \mathrm{wt} \%$ TRGO doping decreases adherence. The microstructural analysis of the lap-shear separated surfaces suggests that TRGO rich zones on the aramid fibers contributed to the loss of adherence. 


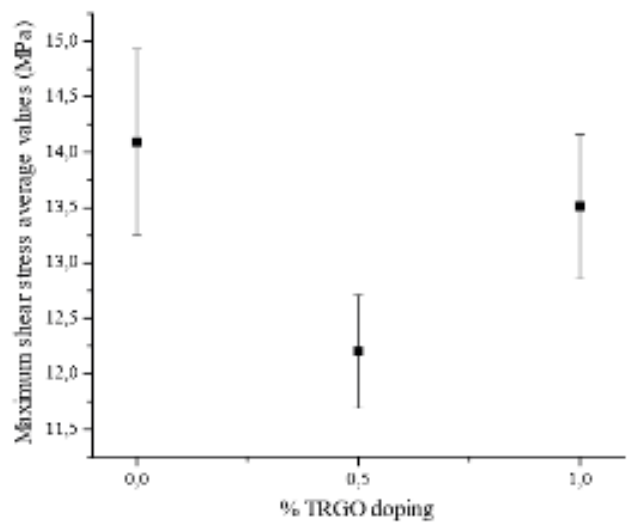

Figure 12: Maximum shear stress measured in Lap-shear test vs. TRGO doping.

Comparing the present results with previous work of CNT doped ARALL [3,4] it is possible to state that: tensile properties in TRGO doped ARALL showed lower differences with those doped with CNT. CNT doping improved the elastic module, contrary to the observations in the present work.

In bending tests, CNT doping showed a higher increase in maximum deflection as compared with TRGO doping. CNT doping shows a higher improvement of fatigue life of ARALL in all the different load levels.

\section{CONCLUSIONS}

Considering the mechanical properties in tensile, bending, fatigue and lap-shear tests in $0.5 \mathrm{wt} \%$ and 1 wt\% TRGO doped ARALL, it is possible to conclude that the ideal addition of TRGO in doping ARALL is $0.5 \mathrm{wt} \%$.

Neither the yield strength nor the UTS is affected by TRGO doping of ARALL. The decreasing in elastic modulus with TRGO doping was important.

The tensile test samples doped with TRGO failed by delamination, as aramid fibers separated completely from the aluminium sheets with the resin adhered mainly to the aluminium sheets rather than to the fibers. As expected, the fractographic analysis of the aluminium sheets themselves, showed no variations compared with non-doped ARALL.

In bending test samples, TRGO doping showed a definitive improvement of maximum deflection, mainly with a $0.5 \mathrm{wt} \%$ TRGO addition. Bending test samples doped with TRGO showed delamination and cracks in resin.

TRGO improved fatigue properties.

Doping ARALL with $0.5 \mathrm{wt} \%$ TRGO strongly decreased resin adherence to aluminium, being detrimental to lap-shear properties.

\section{ACKNOWEDGEMENTS}

Authors would like to acknowledge to "Proyectos Basales", AFOSR (Air Force Office for Science and Research) of United States for financial support, DICYT - USACH (Dirección de Investigación Científica y Tecnológica de la Universidad de Santiago de Chile) and the Aeronautical Polytechnic Academy of the Chilean Air Force.

\section{BIBLIOGRAPHY}

[1] ASDRÚBAL, G., "El Grafeno", Revista Colombiana de Materiales, n. 1, Ene. 2011.

[2] GEIM, A. K., "Graphene, Status and Prospects”, Science, v. 324, pp. 1530-1534, Jun. 2009.

[3] MATURANA, D. A., MORALES, F. A., Evaluación de las propiedades mecánicas de Aramid Aluminium Laminate (ARALL). Estudio con y sin reforzamiento de Nanotubos de Carbono (NTC), Tesis de Ingeniería Aeronáutica, Academia Politécnica Aeronáutica, Fuerza Aérea de Chile, Santiago, Chile, 2014. 
[4] GARLASCHI, E., Estudio de las propiedades mecánicas de Tracción, Flexión y Lap-Shear en Glare con resina reforzada con Nanotubos de Carbono, Tesis de Ingeniería Aeronáutica, Academia Politécnica Aeronáutica, Fuerza Aérea de Chile, Santiago, Chile, 2015.

[5] GARZÓN, C., Desarrollo de Materiales Compuestos de Polipropileno y Nanoestructuras de Carbono, Tesis de Doctorado, Universidad de Chile, Santiago, Chile, 2014.

[6] TANG, L.C., WAN, Y. J., et al., "The effect of graphene dispersion on the mechanical properties of graphene/epoxy composites". Carbon, 60, pp. 16-27, 2013.

[7] RAFIEE, M., RAFFIE, J., WANG, Z., et al., "Enhanced Mechanical Properties of Nanocomposites at Low Graphene Content”. American Chemical Society Nano (ACS Nano), v. 3, n. 12, pp. 3884-3890, Dic. 2009.

[8] RAFIEE, M., RAFFIE, J., WANG, Z., et al., "Fracture and fatigue in graphene nanocomposites". Small, v. 6, n. 2, pp. 179-183, 2010.

[9] POTTS, J., DREYER, D., et al., “Graphene-based polymer nanocomposites”. Polymer, 52, pp. 5-25, 2011.

[10] LIU, Q., L., XUFENG, Z., XINYU, F., et al., "Mechanical and Thermal Properties of Epoxy Resin Nanocomposites Reinforced with Graphene Oxide", Polymer-Plastics Technology and Engineering, v. 51, n. 3, pp. 251-256, Ene. 2012.

[11] KIM, H., ABDALA, A., MACOSKO, C.H., et al., "Graphene/Polymer nanocomposites". Macromolecules, 43, pp. 6515-6530, 2010.

[12] QIU, S.L., WANG, C.S., WANG, Y.T., et al., "Effects of graphene oxides on the cure behaviors of a tetrafunctional epoxy resin”, EXPRESS Polymer Letters, v. 5, n. 9, pp. 809-818, 2011.

[13] SENGUPTA, R., BHATTACHARYA, M., BANDYOPADHYAY, S., et al., "A review on the mechanical and electrical properties of graphite and modified graphite reinforced polymer composites", Progress in Polymer Science, 36, pp. 638-670, 2011.

[14] ATIF, R., SHYHA, I., INAM, F., et al., "Mechanical, Thermal and electrical properties of grapheneepoxy nanocomposites-A review", Polymers, v.8, n.281, 2016.

[15] DOMUN, N., HAVADINIA, H., ZHANG, T., et al., "Improving the fracture toughness and the strength of epoxy using nanomaterials - a review of the current status", Nanoscale, v.7, pp. 10294-10329, 2015. 